\title{
DISTRIBUIÇÃO E ESTRUTURA ETÁRIA \\ DE Ocypode quadrata (FABRICIUS, 1787) \\ (CRUSTACEA, DECAPODA, OCYPODIDAE) \\ EM PRAIA ARENOSA DO LITORAL SUL DO BRASIL
}

\author{
ALBERTO, R. M. F. ${ }^{1}$ e FONTOURA, N. F. ${ }^{2}$ \\ ${ }^{1}$ Museu de Ciências e Tecnologia (MCTPUCRS) (Prédio 40); ${ }^{2}$ Instituto de Biociências (Prédio 12) \\ Pontifícia Universidade Católica do Rio Grande do Sul/ PUCRS, Av. Ipiranga, 6681, C.P. 1429, CEP 90619-900, \\ Porto Alegre, RS, Brasil
}

Correspondência para: Regina Maria de Fraga Alberto, Museu de Ciências e Tecnologia (MCTPUCRS) (Prédio 40), Pontifícia Universidade Católica do Rio Grande do Sul/ PUCRS, Av. Ipiranga, 6681, C.P. 1429, CEP 90619-900, Porto Alegre, RS, Brasil e-mail: regalb@music.pucrs.br

Recebido em 13/08/97 - Aceito em 17/08/98 - Distribuído em 23/02/99

(Com 11 figuras)

\section{ABSTRACT \\ Age structure and spatial distribution of Ocypode quadrata (Fabricius, 1787) on a sandy beach from the south coast of brazil (Crustacea, Decapoda, Ocypodidae)}

Spatial distribution and population structure of Ocypode quadrata (Fabricius, 1787) were studied at Pinhal beach, Rio Grande do Sul, from November/91 to December/93. Analysis of frequency distributions of the ghost crab population was based on indirect census, with burrow diameter measurement. It was identified the presence of two age-groups, with the possible presence of a third one. The maximal life span was estimated to be about 3 years. Burrow diameter/carapace width, lenght/width and weight/width relationships were estimated from samples obtained by excavating burrows and individual capture by traps. These relationship were ajusted by the following equations, respectively: $\mathbf{D T}=0,6648+1,0013 . \mathbf{L} ; \mathbf{C}=0,77 . \mathrm{L}^{1,02}$; and $\mathbf{P}=0,0004 . \mathbf{L}^{3,0876}$ (DT is burrow diameter; $\mathbf{C}$ is the carapace lenght; $\mathbf{L}$ is the carapace width; and $\mathbf{P}$ is the weight). Spatial distribution analysis was performed based on distance and altitude to water line. These crabs dig burrows preferentialy in the central large range of the beach, although having possibility of migration at adverses conditions. Burrow shape also was analysed.

Key words: Ocypode quadrata, ghost-crab, population structure, burrows.

\section{RESUMO}

Analisou-se a distribuição espacial e a estrutura da população do caranguejo-fantasma Ocypode quadrata (Fabricius, 1787), habitante da praia de Pinhal, no litoral do Rio Grande do Sul, no período de novembro de 91 a dezembro de 93. Para a análise da distribuição etária, utilizou-se o censo indireto, baseando-se em medidas aleatórias dos diâmetros das tocas. Constatou-se a existência de 2 grupos etários distintos, com possibilidade de um terceiro grupo. A longevidade foi estimada em até 3 anos. Para as relações diâmetro de toca/largura do cefalotórax, comprimento/largura e peso/largura, foram tomadas amostras de animais, utilizando-se técnicas de escavação e uso de armadilhas específicas. As equações que descrevem estas relações são, respectivamente, DT = 0,6648 + 1,0013.L; $\mathbf{C}=0,77 . \mathrm{L}^{1,02}$; e $\mathbf{P}=0,0004 . \mathbf{L}^{3,0876}$ (DT é o diâmetro da toca; $\mathbf{C}$ é o comprimento da carapaça; $\mathbf{L}$ é a largura da carapaça; e $\mathbf{P}$ é o peso). A análise da distribuição espacial foi realizada através do mapeamento das tocas, baseando-se na distância e no desnível em relação à linha d'água. Constatou-se existir uma preferência pela construção das tocas na grande área central da faixa de praia, podendo haver, no entanto, migração da população em condições adversas. Analisou-se também a morfologia das tocas encontradas, estabelecendo-se padrões para o local.

Palavras-chave: Ocypode quadrata, caranguejo-fantasma, estrutura populacional, tocas. 


\section{INTRODUÇÃO}

O caranguejo-fantasma, Ocypode quadrata (Fabricius, 1787), conhecido vulgarmente como vasa-maré, guaruçá, guriçá, maria-farinha (Santos, 1982) ou siripadoca (Sawaya, 1939), habita praias arenosas, construindo tocas no supralitoral, desde a marca mais alta da linha d'água até a área de encosta das dunas (Rathbum, 1918; Powers, 1977; Ramos-Porto et al., 1978). Representantes desta espécie apresentam grande importância ecológica como consumidores de detritos orgânicos e transferidores de energia entre diferentes níveis tróficos (Phillips, 1940; Fales, 1976; Wolcott, 1978).

Milne \& Milne (1946) constataram que os indivíduos adultos de $O$. quadrata são muito sensíveis ao frio, mas têm mais resistência ao calor, dependendo do grau de umidade de seus canais branquiais. Em estudos feitos no Texas, Haley (1972) registrou a temperatura de $16^{\circ} \mathrm{C}$ como mínima extrema de atividade normal para esta espécie, abaixo da qual os animais permanecem dormentes em suas tocas construídas acima da linha mais alta de maré. Leber (1982) confirmou esta informação em estudos feitos na Carolina do Norte, tendo registrado a presença de $O$. quadrata somente na primavera, verão e outono. $\mathrm{O}$ hábito de cavar tocas, bem como os padrões das mesmas, foram amplamente estudados por Coues (1871), Cowles (1908), Sawaya (1939) e Phillips (1940), para $O$. quadrata. Além dos trabalhos citados, Wolcott (1978) utilizou a contagem de tocas para analisar a densidade das mesmas por metro linear de praia, em diferentes meses do ano. Fisher \& Tevesz (1979) estudaram o padrão de distribuição de tocas de jovens e adultos em praias dos Estados Unidos.

Wolcott \& Wolcott (1984), analisando a influência do tráfego na faixa de praia, constataram que o hábito de se ocultarem em tocas é importante fator de sobrevivência para $O$. quadrata. Estudo semelhante foi realizado por Steiner \& Leatherman (1981) na Virgínia, Estados Unidos. Os hábitos alimentares e o comportamento de $O$. quadrata foram detalhados, principalmente, por Coues (1871) (como O. arenaria), Cowles (1908), Sawaya (1939), Phillips (1940) (como O. albicans), Milne \& Milne (1946), Fales (1976), Powers (1977), Wolcott (1978) e Robertson \& Pfeiffer (1982). Schöne (1968) e Milne \& Milne (1946) estudaram o caráter agressivo desta espécie. A reprodução de $O$. quadrata (como O.arenaria) foi observada por Cowles (1908) na Flórida, que citou, como período provável, a primavera e o início do verão.

A gametogênese em $O$. quadrata foi estudada no Texas, por Haley (1969) que relacionou padrões de crescimento relativo com maturidade sexual. Segundo Haley (1972), existem dois picos de maturação em fêmeas: primavera e verão. $\mathrm{O}$ autor registrou animais em cópula nos meses de maio, agosto e setembro (primavera e verão) e estimou valores prováveis para os períodos de desenvolvimento entre a cópula, eclosão dos ovos e o primeiro estágio de juvenil. Segundo Williams (1984), o acasalamento ocorre em dois picos anuais (primavera e verão) existindo relação entre o período reprodutivo e a temperatura. O desenvolvimento pós-embrionário de espécies do gênero Ocypode foi estudado por Crane (1940).

\section{MATERIAL E MÉTODOS}

Os trabalhos de campo foram realizados no município de Balneário Pinhal/ RS, durante o período compreendido entre novembro de $1991 \mathrm{e}$ dezembro de 1993 (Fig. 1).

A praia de Pinhal é um balneário marítimo situado às margens do Oceano Atlântico $\left(30^{\circ} \mathrm{S}\right.$; $\left.50^{\circ} \mathrm{W}\right)$. Apresenta uma faixa litorânea cuja largura oscila em torno de $50 \mathrm{~m}$, medidos desde a linha d'água até a base exterior das dunas costeiras. Esta medida, no entanto, é bastante variável, podendo atingir cerca de $100 \mathrm{~m}$ com maré baixa ou até desaparecer quando o mar, em situação de ressaca, atinge o sopé das dunas. Esta característica é típica das praias da costa do litoral norte do Rio Grande do Sul que, em toda a sua extensão, é francamente dominada pela ação das ondas, devido à sua configuração praticamente retilínea (Tomazelli \& Villwock, 1992).

As dunas costeiras, que já sofreram interferências da atividade humana, apresentam altura média em torno de $3 \mathrm{~m}$, medidos de sua base, e se dispõem continuadamente paralelas ao mar. Muitas delas apresentam vegetação de caráter halófito e heliófito, tais como Philoxerus portulacoides (capotiraguá), Senecio crassiflorus (macelagraúda), Paspalum distichum (capim-da-praia), Spartina ciliata (capim-das-dunas) e Hydrocotyle bonariensis (acariçoba). 


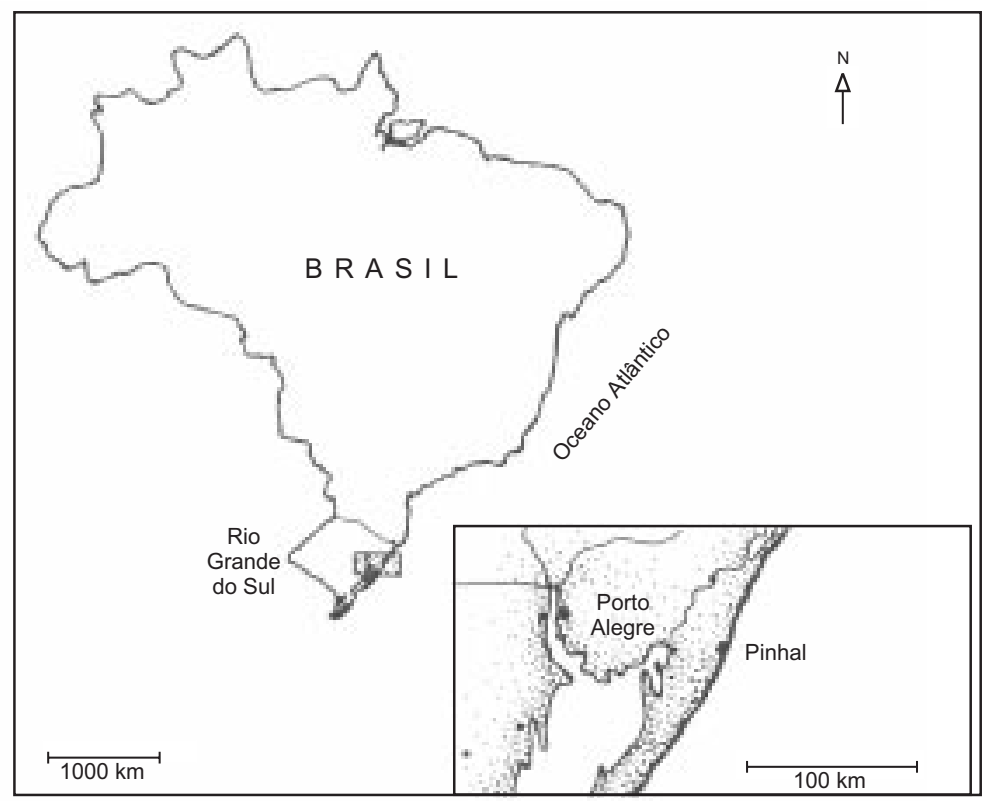

Fig. 1- Localização da área de amostragem; praia de Pinhal, município de Balneário Pinhal, Rio Grande do Sul.

Para análise da estrutura etária, utilizou-se o censo indireto baseado nas medidas mensais dos diâmetros das tocas. A fim de minimizar o impacto da atividade humana e o conseqüente nível de interferência, considerou-se área de amostragem aquela que se iniciava a cerca de $1 \mathrm{~km}$ do centro urbano de Pinhal, em direção ao Sul, com extensão máxima de $2 \mathrm{~km}$, que corresponde às proximidades da praia de Magistério. A cada amostragem, foram mensuradas as aberturas de tocas encontradas aleatoriamente, nesta área. As medidas foram realizadas com paquímetro de precisão de $0,1 \mathrm{~mm}$ e os dados foram agrupados por classes de tamanho para análise da distribuição de freqüências. Por ocasião de cada amostragem, foi anotada a temperatura do ar.

Para a relação entre o diâmetro da toca e o tamanho do respectivo animal, foram realizadas escavações e capturas por armadilhas.

Os espécimes capturados foram medidos e devolvidos ao seu hábitat natural, com exceção de alguns exemplares levados ao laboratório para pesagem, em balança semi-analítica com precisão de $0,01 \mathrm{~g}$.

Para a relação entre o diâmetro da toca e a largura do cefalotórax, utilizou-se a equação da reta: $\mathbf{D T}=\mathbf{a}+\mathbf{b} . \mathbf{L}$, em que Dt é o diâmetro da toca $(\mathrm{mm})$; L é a largura do cefalotórax (mm); e a e b são parâmetros. A relação entre o peso e a largura do cefalotórax foi baseada na seguinte equação: $\mathbf{P}=\mathbf{a} \cdot \mathbf{L}^{\mathbf{b}}$, em que $\mathbf{P}$ representa o peso (g), L é a largura do cefalotórax ( $\mathrm{mm}$ ) e a e b são parâmetros. Para a relação entre comprimento e largura do cefalotórax, utilizou-se a expressão: $\mathbf{C}=$ $\mathbf{a} . \mathbf{L}^{\mathbf{b}}$, em que $\mathbf{C}$ é o comprimento, $\mathbf{L}$ é a largura do cefalotórax (mm), a e b são parâmetros.

Para a análise da distribuição espacial, na faixa de praia estudada, foram realizadas amostragens por meio de transectos perpendiculares à praia com $20 \mathrm{~m}$ de largura, divididos em faixas de $5 \mathrm{~m} \times 5 \mathrm{~m}$, no qual o ponto zero correspondeu ao limite médio do alcance das ondas e o último "quadrats" foi estabelecido pelo local extremo da ocorrência de tocas. Em cada "quadrats" foram medidas todas as tocas, registrando-se sua localização. Para a análise da distribuição espacial de acordo com a declividade da praia, foram traçadas faixas paralelas ao mar, em diversas altitudes em relação à linha d'água. A variação entre uma faixa e outra, foi determinada em $0,10 \mathrm{~m}$. Para o estudo da morfologia das tocas, extraíram-se moldes de uma amostra aleatória, de vários tamanhos, utilizando-se uma mistura de gesso e água, na proporção aproximada de 1:4. 


\section{RESULTADOS E DISCUSSÃO}

Após 3 anos de freqüentes observações na praia de Pinhal, constatou-se que a população de O. quadrata é muito sensível às modificações climáticas. Variações de temperatura, direção e intensidade dos ventos e do nível de alcance das ondas interferem diretamente em suas atividades, ao ponto de, em condições adversas, nenhum sinal desta espécie ser observado na praia. Este fato já havia sido registrado por Cowles (1908), Sawaya (1939), Phillips (1940), Milne \& Milne (1946), Schmitt (1968) e Wolcott (1978), os quais enfatizaram o hábito destes caranguejos de se recolherem às suas tocas em condições adversas, fechando a entrada de tal modo que se torna impossível localizá-las. Este fato dificultou sobremaneira os trabalhos de campo, que ficaram restritos aos dias e horas em que as condições ambientais estivessem totalmente favoráveis. Segundo observações pessoais, um dos principais fatores que interferem na atividade destes animais é a temperatura.

Durante os trabalhos realizados na praia de Pinhal, confirmou-se o limite mínimo de temperatura $\left(16{ }^{\circ} \mathrm{C}\right)$ registrado por Haley (1972), constatando-se, entretanto, que os animais voltam à atividade tão logo a mesma atinja níveis ideais, independente da época do ano. Como o inverno nesta região alterna dias frios com outros de temperaturas mais amenas, é comum, nestes dias, observar a população de $O$. quadrata em suas atividades normais. Entretanto, a maior movimentação de animais saindo de suas tocas ocorre apenas por volta das $10 \mathrm{~h}$ ou em horário mais próximo ao meio-dia, quando a temperatura diária atinge níveis mais altos, ao contrário do período de verão, em que as atividades dos caranguejos se intensificam ao final da tarde.

Esta variação em densidade de animais ativos sugere a existência também de um limite máximo de temperatura para esta espécie, o qual pode ser ultrapassado nos horários mais quentes dos dias de verão, afastando os animais da superfície. Além da temperatura, a velocidade e direção dos ventos são também fatores fundamentais de interferência. Através de observações pessoais, constatouse que, mesmo com temperaturas ideais (em torno de $25^{\circ} \mathrm{C}$ ), a presença de vento Nordeste, com intensidade moderada a forte, leva os caranguejos a se refugiarem nas tocas. Neste caso, os animais fecham completamente suas aberturas, que a própria areia carregada pelo vento, termina por ocultar.

O fenômeno da ressaca, bastante comum nesta região, foi observado várias vezes durante os trabalhos de campo, também provocando o ocultamento da população por vários dias, independente da temperatura ou das condições do tempo. Em períodos de menor intensidade, quando a água não cobria totalmente a faixa de praia, as tocas apareciam em áreas mais altas, próximas às dunas e entre elas, em um visível deslocamento de seu padrão normal. A incidência, neste caso, era muito pequena e restrita aos animais mais jovens. Quando o nível da água baixava ao seu normal e começavam a surgir áreas de areia seca, a população de $O$. quadrata voltava a distribuir-se ao longo da praia.

As Figs. 2, 3 e 4, traçadas a partir de amostragens diferentes, mostram a densidade e o diâmetro médio de tocas de O. quadrata, em função da distância do ponto médio de alcance das ondas. Os resultados das análises efetuadas demonstram que existe uma faixa ideal para a construção das tocas, que se situa entre 15 e $75 \mathrm{~m}$ de distância da linha d'água. Para os dados coletados em 11 e 12 de fevereiro $(\mathbf{n}=143)$, constatou-se que a maior freqüência de tocas ocorreu na faixa de 55 a $60 \mathrm{~m}$ de distância da linha d'água, sendo que o diâmetro médio neste local foi avaliado em 23,45 mm (Fig. 2). Acima desta marca, as tocas diminuíram em número e aumentaram em diâmetro médio, caracterizando uma preferência em localização dos animais adultos, cujo diâmetro ultrapassou $30 \mathrm{~mm}$. À medida que se deslocam para as proximidades da linha d'água, as tocas diminuem em número e em diâmetro médio. No entanto, foram encontradas tocas de animais pequenos e médios, com diâmetro de até $20 \mathrm{~mm}$, em toda a extensão da faixa central de praia, compreendida entre 25 e $60 \mathrm{~m}$ de distância da linha d'água. A baixa freqüência de tocas na faixa localizada a $40 \mathrm{~m}$ do mar pode ser justificada pela utilização da mesma para eventual trânsito de veículos na praia, na época em que foi realizada esta amostragem. A Fig. 3, traçada a partir de coletas realizadas em 16 e 17 de fevereiro, apresenta uma concentração de tocas compreendida entre $25 \mathrm{e}$ $55 \mathrm{~m}$ de distância da linha d'água, com maior incidência em torno dos $40 \mathrm{~m}$. 


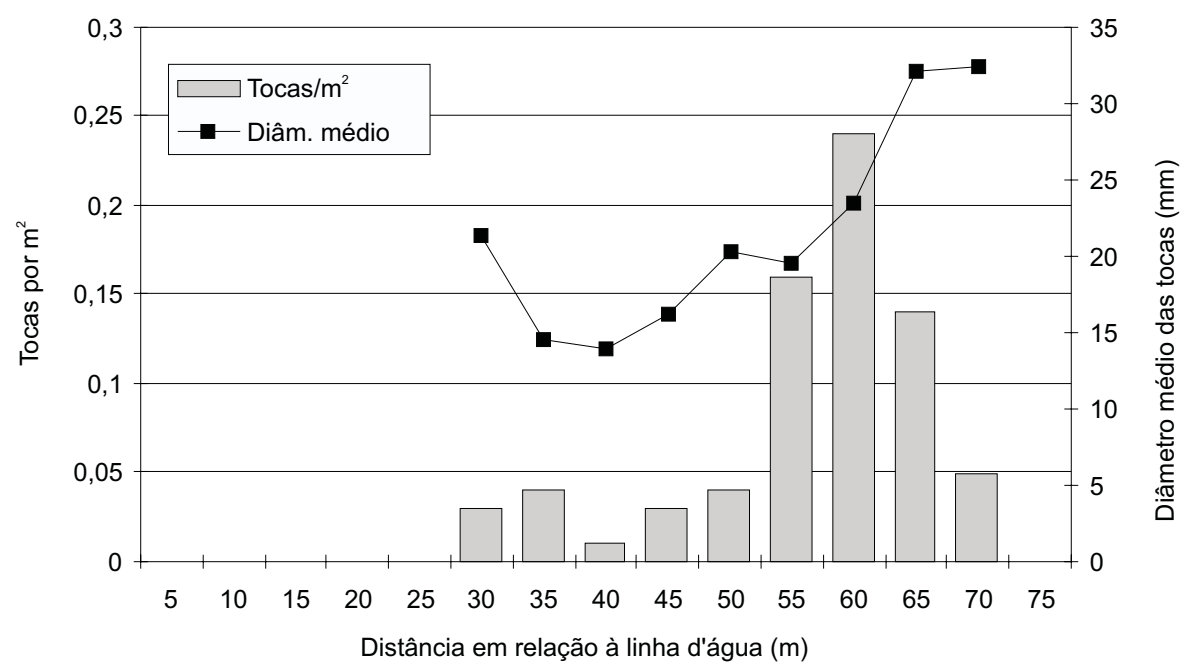

Fig. 2 - Densidade e diâmetro médio de tocas de Ocypode quadrata, em função da distância em relação à linha média da zona de lavagem. Amostragens realizadas em 11 e 12 de fevereiro de 1991; 143 tocas observadas.

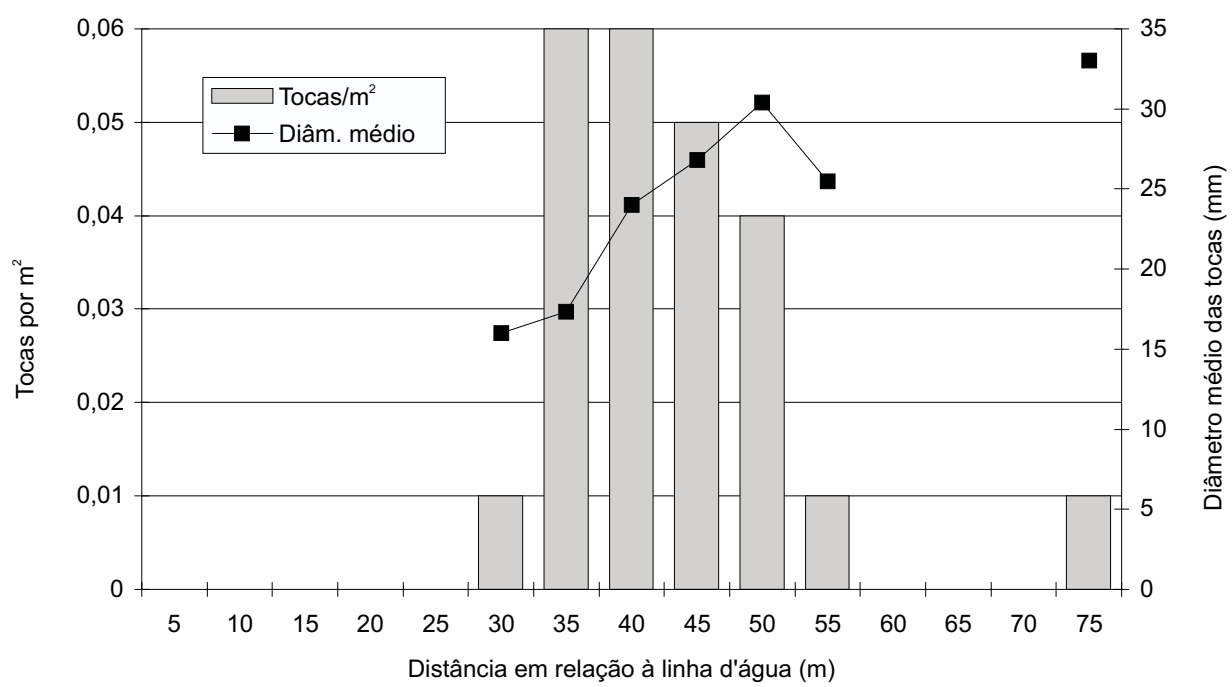

Fig. 3 - Densidade e diâmetro médio de tocas de Ocypode quadrata, em função da distância em relação à linha média da zona de lavagem. Amostragens realizadas em 16 e 17 de fevereiro de 1991; 46 tocas observadas.

Esta amostragem foi realizada após um período de ressaca, quando o mar avançou sobre a faixa de praia durante cerca de 3 dias, cobrindoa quase que totalmente em seu momento máximo. Isto justifica o pequeno número de tocas encontrado, mesmo tendo continuado a coleta de dados por 2 dias consecutivos $(n=46)$.

Constatou-se também um aumento gradativo no diâmetro médio das tocas, à medida que se afastavam da orla, tendo o limite máximo localizado entre 50 a $55 \mathrm{~m}$ de distância. Os registros isolados que ocorreram a $75 \mathrm{~m}$ da linha d'água localizavam-se sobre as dunas e correspondiam a indivíduos grandes, com mais de $30 \mathrm{~mm}$ de largura, que, provavelmente, se deslocaram para lá devido à subida das águas. É possível que o número de indivíduos ocorrentes nas dunas seja superior ao registrado, uma vez que a areia seca e solta pode cobrir a abertura das tocas, impedindo sua perfeita localização. 


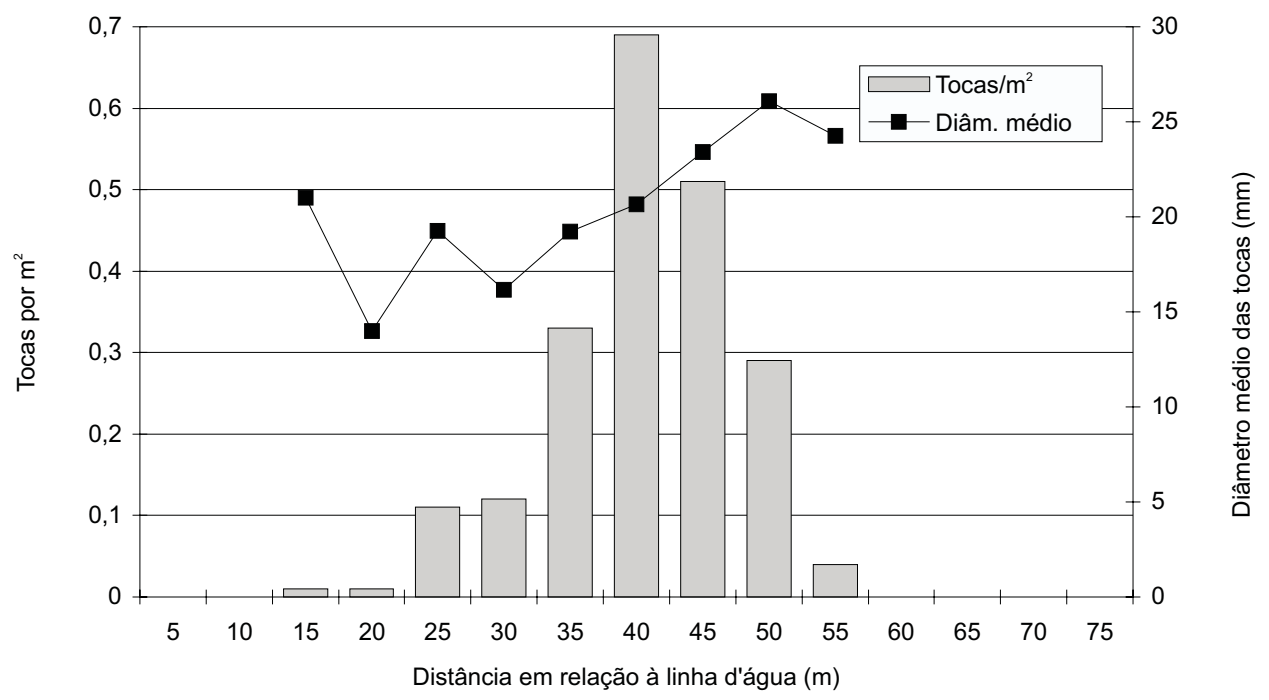

Fig. 4 - Densidade e diâmetro médio de tocas de Ocypode quadrata, em função da distância em relação à linha média da zona de lavagem. Amostragem realizada em 3 de março de 1991; 211 tocas observadas.

A Fig. 4, que apresenta os resultados de coleta realizada em 3 de março $(n=211)$, mostra igualmente uma maior concentração de tocas na faixa mediana, situada em torno de $40 \mathrm{~m}$ de distância da linha d'água, a qual diminui para ambos os extremos. O diâmetro médio das tocas com algumas exceções, aumentou proporcionalmente com a distância em relação ao mar. Os dados de campo registraram tocas de indivíduos pequenos e médios, com diâmetros entre 10 e $25 \mathrm{~mm}$, distribuídas desde $10 \mathrm{~m}$ até $55 \mathrm{~m}$ da linha d'água; enquanto que, tocas de indivíduos maiores, cujos diâmetros situavam-se entre 25 a $30 \mathrm{~mm}$, apareceram somente além dos $35 \mathrm{~m}$ de distância; e ainda, tocas com diâmetros superiores a estes só ocorreram em distâncias acima de $40 \mathrm{~m}$. Nesta amostragem, constatou-se uma maior proximidade da linha d'água, com registros de tocas até $15 \mathrm{~m}$ da mesma. Analisando as três figuras citadas, podese verificar que existe uma faixa preferencial para a construção das tocas, considerando-se a distância da linha d'água, com maior incidência na área central de praia. Indivíduos de diferentes idades também se distribuem mediante determinado padrão, no qual os maiores tem preferência pelas áreas mais afastadas, conforme já constatado por Frey \& Mayou (1971) (apud Duncan, 1986). Tocas de indivíduos de tamanho médio (em torno de 15 a $20 \mathrm{~mm}$ ), no entanto, podem ser encontrados em praticamente toda a faixa de praia. Steiner \&
Leitherman (1981) sugeriram que a dispersão de caranguejos sobre todo o perfil da praia pode ocorrer devido ao hábito alimentar destes animais. A praia de Pinhal apresenta distribuição de alimento para $O$. quadrata em toda a sua largura, não só pela utilização humana (no verão) como também pelos restos de peixes e mariscos deixados por pescadores e espalhados pela areia durante as ressacas e marés mais altas. Portanto, a justificativa sugerida pelos autores poderia se enquadrar neste caso. Constatou-se também que a densidade populacional nas proximidades do Clube de Pesca local tende a aumentar visivelmente, se comparada a zonas mais desertas. Possivelmente, os hábitos desta espécie assemelham-se àqueles registrados para O. gaudichaudii, por Koepcke (1953). Segundo este autor, quando encontram uma boa fonte de alimentação, os caranguejos iniciam a construção de novas tocas, permanecendo pelas proximidades.

As Figs. 5 e 6, as quais foram traçadas a partir de amostragens diferentes, mostram a densidade de tocas em relação à altitude do terreno. Na Fig. 5 , que corresponde aos resultados dos dias $25 \mathrm{e}$ 27 de fevereiro $(\mathbf{n}=196)$, constata-se que não foi encontrada nenhuma toca em altitude inferior a $0,50 \mathrm{~m}$ e, mesmo nesta faixa e nas seguintes, elas ocorreram em baixa densidade. A maior concentração de tocas apareceu na zona mediana da praia, correspondendo a uma altitude de cerca de $1 \mathrm{~m}$ 
da linha d'água. A partir daí, em direção às dunas, a quantidade de tocas tende a diminuir, mas a densidade das mesmas por metro quadrado é gradativamente maior, com algumas exceções. Isto ocorre porque a variação de desnível da praia acentua-se mais à medida que se aproxima do topo das dunas, cuja altitude máxima, neste local, correspondeu a cerca de $4 \mathrm{~m}$.

Considerando-se a distância em relação ao mar, constatou-se que a toca mais próxima situava-se a cerca de $10 \mathrm{~m}$ da linha d'água, em desnível de $0,50 \mathrm{~m}$. A toca mais extrema distava cerca de $50 \mathrm{~m}$ do mar e localizava-se já na encosta da duna, em altitude aproximada de $1,80 \mathrm{~m}$. A faixa de desnível onde ocorreu maior incidência de tocas situava-se entre 20 e $40 \mathrm{~m}$ do mar, em altitude média aproximada de $1 \mathrm{~m}$ em relação à linha d'água.

Outra amostragem, realizada na mesma área, após intervalo de 15 dias, forneceu resultados um pouco diferentes, conforme apresentado na Fig. $6(\mathbf{n}=179)$. A primeira faixa em que se registrou presença de tocas localizava-se a $0,80 \mathrm{~m}$ da linha d'água e a maior concentração estava em torno de $1,40 \mathrm{~m}$ de altitude. A quantidade de tocas por $\mathrm{m}^{2}$ não apresentou grandes variações, até a altitude de $2 \mathrm{~m}$, oscilando entre o mínimo de 0,12 ao máximo de 0,24 .

Este último dado coincide também com o maior número de tocas por faixa. Os índices mais altos de 0,69 e 0,70 tocas $/ \mathrm{m}^{2}$, registrados em altitude de 2,20 m e 2,40 m, sofreram interferên- cia do reduzido comprimento das faixas neste ponto, conforme citado anteriormente, já que se situam na encosta da duna. Ocorreram tocas também sobre as dunas, a cerca de 3,40 e $3,80 \mathrm{~m}$ de altitude. Esta distribuição homogênea constatada nesta amostragem pode ser explicada pelo fato de serem as tocas quase que exclusivamente de indivíduos jovens.

Com exceção daquelas encontradas sobre as dunas, cujo diâmetro médio era de $27,75 \mathrm{~mm}$, todas as tocas aferidas nesta amostragem, encontravamse entre $6,55 \mathrm{~mm}$ e $13,15 \mathrm{~mm}$ de diâmetro, apesar do caráter aleatório da técnica utilizada. Comparando-se ambas as amostragens (Figs. 5 e 6), observou-se um aumento da faixa de praia em cerca de $10 \mathrm{~m}$, constatado pela mensuração em linha reta perpendicular ao mar, desde o ponto médio de alcance das ondas, até um marco referencial, fixado no ponto mais alto das dunas desde o início dos trabalhos. Os resultados destas amostragens reforçam a observação de preferência destes animais em construírem suas tocas na grande área central da faixa de praia, reservando uma determinada distância da linha d'água. Resultados semelhantes foram constatados por Koepcke (1953), para $O$. gaudichaudii, em praia arenosa da costa peruana. Apesar das peculiaridades de cada ambiente e da diferença entre as espécies, pode-se constatar que, em geral, os animais distribuem-se nas zonas intertidal e de praia seca, com densidades variáveis conforme a proximidade da linha d'água.

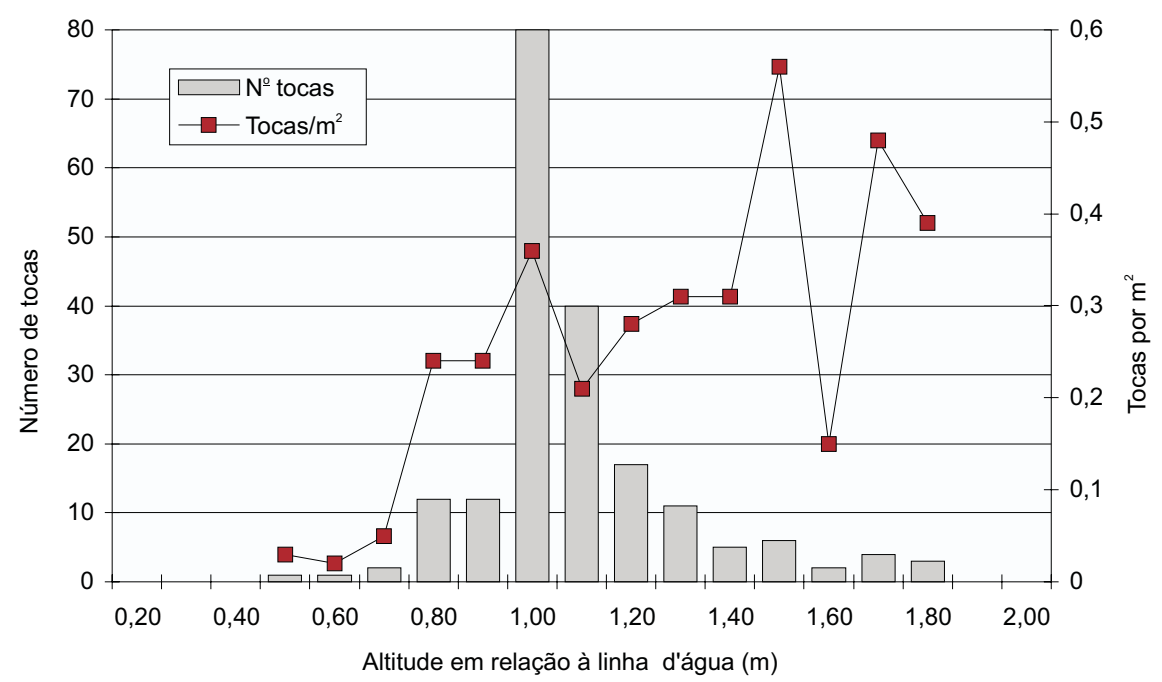

Fig. 5 - Densidade de tocas de Ocypode quadrata em função da altitude do terreno, em relação à linha média da zona de lavagem. Amostragens realizadas em 25 e 27 de fevereiro de 1993; 196 tocas observadas. 


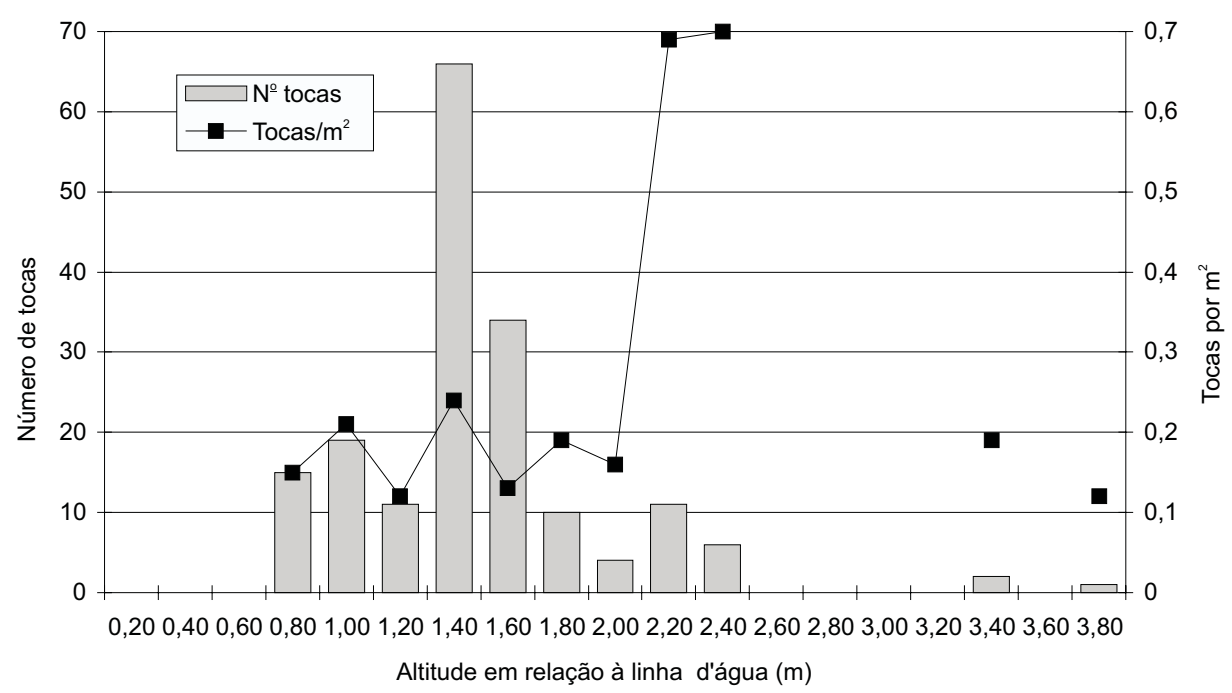

Fig. 6 - Densidade de tocas de Ocypode quadrata em função da altitude do terreno, em relação à linha média da zona de lavagem. Amostragens realizadas em 14 de março de 1993; 179 tocas observadas.

Os resultados obtidos na praia de Pinhal demonstram, igualmente, a possibilidade de migração da população perpendicularmente ao mar, cujo fator determinante esteve relacionado com as condições ambientais, principalmente no que se refere à distância da linha d'água.

As tocas de O. quadrata, encontradas durante os trabalhos, apresentavam morfologia e profundidades variadas, podendo ser agrupadas por determinados padrões. Animais pequenos, com diâmetro médio em torno de $8 \mathrm{~mm}$, eram encontrados em tocas retas, verticais, de pouca profundidade (aproximadamente 15 a $20 \mathrm{~cm}$ ) (Fig. 7a). Tocas com diâmetro de abertura maior, apresentavam-se mais profundas e, geralmente, inclinadas em ângulo variável com a superfície, podendo apresentar sua porção terminal um pouco mais alargada e curva, com tendência para a horizontalidade (Figs. 7b, c e d).

Nas escavações feitas, constatou-se que este era o local onde se encontrava o caranguejo quando em repouso. Esta curvatura, em algumas tocas, era bastante acentuada, dando-lhe aspecto de "U", embora a porção terminal nunca atingisse a superfície (Fig. 7e). As tocas de indivíduos grandes, com diâmetro em torno de $30 \mathrm{~mm}$, inclinavam-se profundamente para baixo das dunas, dificultando sua escavação ou obtenção de moldes devido à areia solta. Um outro tipo encontrado apresentava uma ramificação secundária, bem mais estreita que o túnel principal da toca. Este canal dirigia-se à superfície mas não se abria no exterior (Fig. 7f). Estes tipos de tocas encontrados podem ser comparados com aqueles referidos por Cowles (1908), para praias da Flórida. As tocas de jovens, também referidas por Cowles (1908), puderam ser facilmente identificadas devido ao seu diâmetro reduzido, à sua pouca profundidade e à sua posição vertical. Além destes, o autor citado caracteriza como outro tipo, tocas inclinadas, mais profundas e sem ramificação, que também ocorreram no Pinhal. No entanto, foram encontradas tocas em curva, conforme já descritas, que tanto poderiam ser incluídas neste terceiro tipo de Cowles (1908) como em uma classificação a parte devido às suas particularidades. Willians (1984) registrou esta forma de "U", mas em tocas ramificadas. Sabese, no entanto, que existe grande individualidade na construção das tocas e que estas podem apresentar diferentes formas em latitudes diferentes (Cowles, 1908; Phillips, 1940; Hill \& Hunter, in Williams, 1984). Todos os tipos de tocas, encontradas no Pinhal, enquadram-se nas forma gerais estabelecidas por Takahasi (1935) para o gênero Ocypode.

As análises de distribuição e estrutura etária de $O$. quadrata foram facilitadas pela correlação existente entre a largura do cefalotórax e o diâmetro da toca, permitindo a utilização de senso indireto no levantamento de dados. 


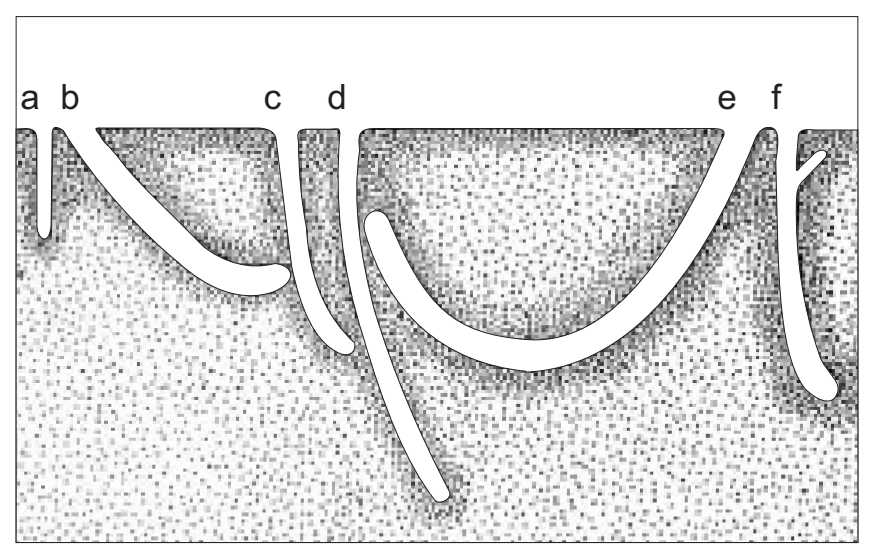

Fig. 7 - Padrões de tocas encontradas durante os trabalhos de campo na praia de Pinhal, município de Balneário Pinhal, Rio Grande do Sul. A variação no diâmetro é proporcional à largura da carapaça do animal. Toca de indivíduo muito jovem (a); tocas de indivíduos maiores, mostrando diferentes inclinações e profundidades (b, c, d); toca em forma de "U" (e); toca com ramificação secundária (f).

Este fato também foi considerado por Wolcott (1978) e Fisher \& Tevesz (1979) em estudos ecológicos nesta espécie. Comparando-se as medidas obtidas de largura do cefalotórax e diâmetro da toca, em uma amostra de 170 indivíduos, constatou-se existir uma relação direta que foi representada pela seguinte equação: $\mathbf{D T}=0,6648+$ 1,0013.L $(\mathbf{r}=0,97)$, em que DT é o diâmetro da toca e $\mathbf{L}$ é a largura do cefalotórax (ambos em $\mathrm{mm}$ ) (Fig. 8). Os dados biométricos dos indivíduos (comprimento e largura do cefalotórax) apresentaram uma relação direta (Fig. 9). Para a população estudada, em uma amostra de 43 indivíduos, a relação entre comprimento e largura foi descrita pela seguinte equação: $\mathbf{C}=0,77 \cdot \mathbf{L}^{1,02}(\mathbf{r}=0,99)$, em que $\mathbf{C}$ é o comprimento e $\mathbf{L}$, a largura da carapaça (ambos em $\mathrm{mm}$ ).

Nesta mesma amostra aleatória, $22 \%$ dos indivíduos capturados eram machos, $31,82 \%$ eram fêmeas e $49,07 \%$ eram jovens. Para esta classificação, estabeleceu-se a largura de $20 \mathrm{~mm}$ de carapaça como limite entre jovens e adultos, após ter-se constatado que, a partir desta medida, já é visível o dimorfismo sexual. Neste caso, não se considerou o fator maturidade sexual, mas apenas as diferenciações morfológicas entre jovens e adultos, mais visíveis nas fêmeas devido às modificações que ocorrem no abdômen.

As menores tocas encontradas apresentavam $5,2 \mathrm{~mm}$ e $5,8 \mathrm{~mm}$ de diâmetro, o que corresponde a animais com larguras de carapaça estimadas em torno de 4,5 $\mathrm{mm}$ e $5,1 \mathrm{~mm}$, respectivamente. Estes tamanhos mínimos de tocas mensuradas foram registrados no mês de março; mas, com pouca diferença de tamanho $(6,0 \mathrm{~mm})$, foram encontradas tocas em janeiro, fevereiro, junho, julho e outubro. No mês de novembro, as menores tocas mediam $6,4 \mathrm{~mm}$; e, em dezembro, todas as tocas encontradas apresentavam diâmetro igual ou superior a 9,7 mm. A maior toca foi registrada no mês de agosto medindo 40,4 $\mathrm{mm}$ de diâmetro, correspondendo a indivíduos com, aproximadamente, $39,7 \mathrm{~mm}$ de largura.

$\mathrm{O}$ menor indivíduo capturado media $5,2 \mathrm{~mm}$ de largura do cefalotórax e, os maiores espécimes, $34,4 \mathrm{~mm}$ (um dos quais, encontrado em toca com 40,0 $\mathrm{mm}$ de diâmetro). Mediante estas informações, pode-se deduzir que, no local estudado, os indivíduos maiores não alcançam as dimensões citadas por Sawaya (1939), o qual, pesquisando uma população desta espécie na enseada de Guarujá (São Paulo), observou tocas com diâmetros em torno de $50 \mathrm{~mm}$, ou Milne \& Milne (1946) que registraram indivíduos com $48 \mathrm{~mm}$ de largura, em Nova Jersey. Da mesma forma, enquanto Crane (1940) registrou megalopas desta espécie com largura de 4,6 a 5,3 mm, no Pinhal foram encontrados caranguejos juvenis com 5,2 mm, já habitando suas tocas. Estes dados demonstram que os exemplares de $O$. quadrata, na região estudada, apresentam porte menor do que aqueles citados na literatura e referidos para outros locais.

Durante todo o trabalho de campo, foram capturadas fêmeas com largura de carapaça que 
variou de $21,8 \mathrm{~mm}$ a $34,4 \mathrm{~mm}$. A única fêmea ovada foi coletada no mês de junho e media 23,6 $\mathrm{mm}$ de comprimento e $29,6 \mathrm{~mm}$ de largura do cefalotórax. Ela foi encontrada em meio à areia seca, na base de uma duna, em toca de pouca profundidade e não parecia completamente saudável. Portava, em seu abdômen, cerca de 9.000 ovos, com diâmetro médio de $250 \mathrm{~mm}$. Apesar de terem sido realizadas outras escavações na mesma área e em áreas semelhantes, com as técnicas utilizadas, nenhuma outra fêmea ovada foi encontrada. Portanto, deduziu-se que, para sua captura, torna-se necessária maior especialização das técnicas de coleta, as quais devem se adaptar também às condições rústicas das praias de mar aberto.

A relação entre o peso e a largura do cefalotórax, para uma amostragem de 54 indivíduos, foi descrita pela seguinte equação: $\mathbf{P}=0,0004$. $\mathbf{L}^{3,0876}(\mathbf{r}=0,99)$, em que $\mathbf{P}$ é o peso, em gramas; e $\mathbf{L}$ é a largura, em mm (Fig. 10). O menor indivíduo capturado pesava $0,10 \mathrm{~g}(\mathbf{L}=5,6 \mathrm{~mm})$; e o maior indivíduo que teve seu peso avaliado pesava $21,54 \mathrm{~g}(\mathbf{L}=34,4 \mathrm{~mm})$. Esta relação foi também apresentada por Wolcott (1978) em estudos realizados com esta espécie.

A Fig. 11 apresenta as distribuições mensais de freqüências de diâmetros de tocas. Embora não se observe nítido deslocamento modal, vários aspectos da biologia de $O$. quadrata podem ser identificados. Inicialmente, constata-se a presença de jovens em praticamente todas as amostragens. Tal fato sugere que a reprodução ocorra durante todo o ano. Esta constatação pode ser corroborada pelo fato de ter sido capturada uma fêmea ovada em escavações realizadas também no mês de junho, ou seja, no início do inverno.

Os estudos de Haley (1972) com fêmeas de O. quadrata já sugeriam atividades copulatórias cíclicas com picos na primavera e no verão, confirmando as hipóteses de Cowles (1908), embora tenham sido encontrados animais em cópula também no outono. Considerando-se o período de 30 dias entre a eclosão e o primeiro estágio semiterrestre (Haley, op. cit.), pode-se estabelecer que os pequenos caranguejos, com diâmetro de toca em torno de $6 \mathrm{~mm}$ (que corresponde a $\mathbf{L}=$ $5,34 \mathrm{~mm}$ ), surgidos na praia no mês de janeiro, eclodiram provavelmente em dezembro. A coluna representativa deste grupo, no gráfico, aumentou gradativamente no período de janeiro à março, demonstrando um acréscimo de jovens na população, em número maior do que o grupo em crescimento.

Este recrutamento é reforçado pelo registro de animais menores ainda nos meses de fevereiro e março. A partir de abril, continuam ingressando jovens na população, mas em quantidades progressivamente menores do que aqueles em crescimento. Isto é demonstrado pelo deslocamento da moda entre março e junho.

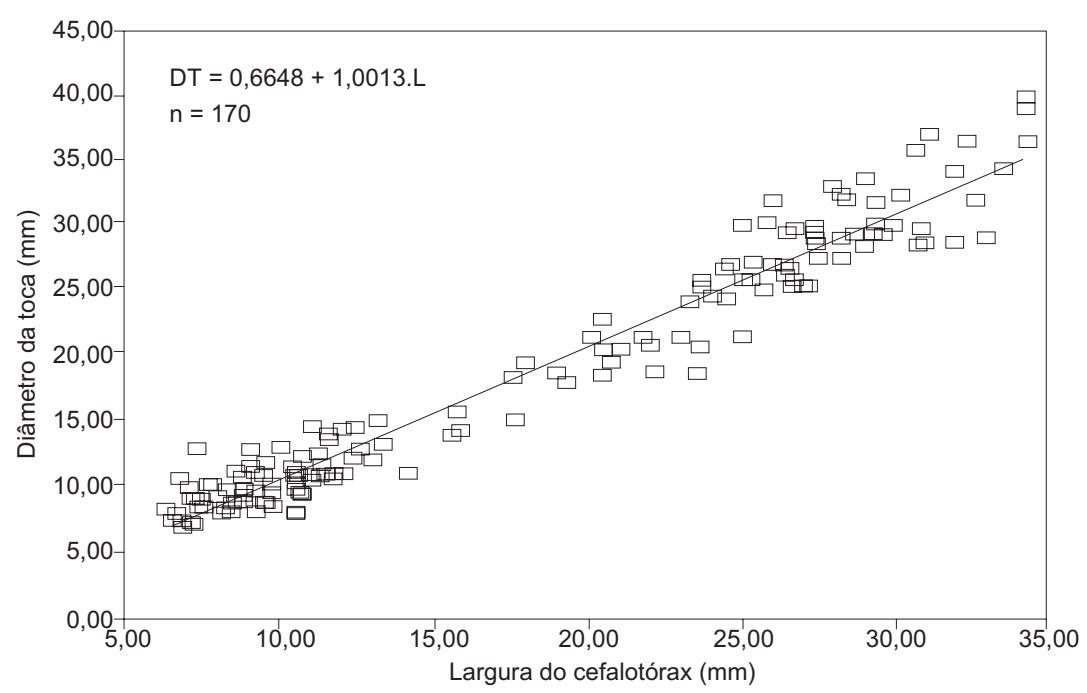

Fig. 8 - Relação entre o diâmetro da toca e a largura da carapaça de Ocypode quadrata, na praia de Pinhal, município de Balneário Pinhal, RS. 


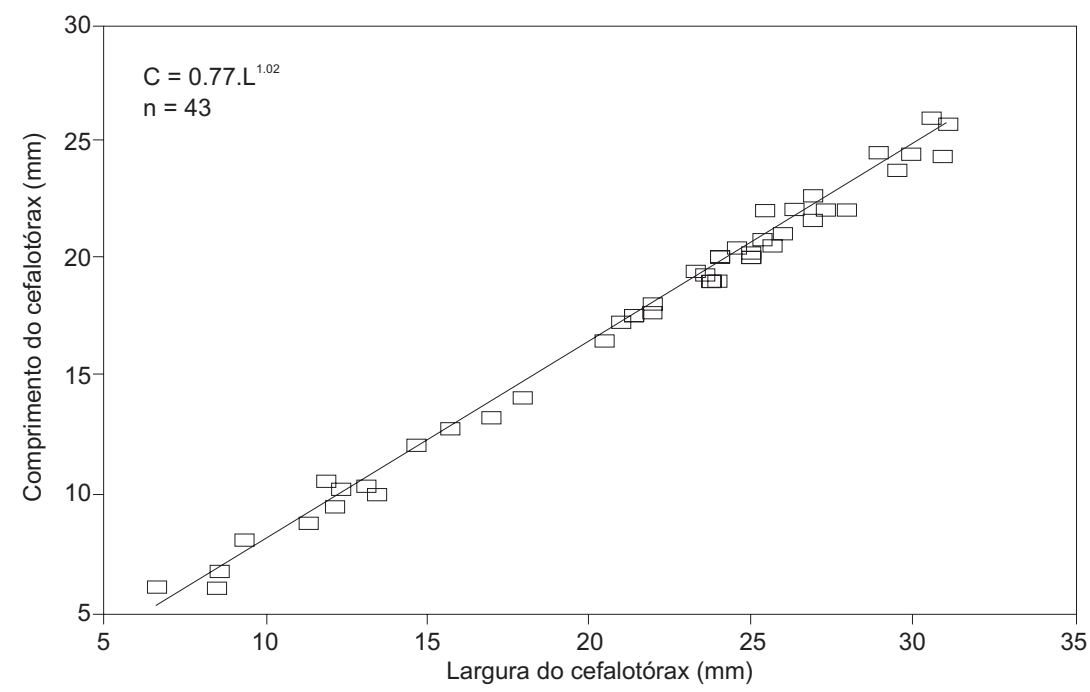

Fig. 9 - Relação entre o comprimento e a largura do cefalotórax de Ocypode quadrata, na praia de Pinhal, município de Balneário Pinhal, RS.

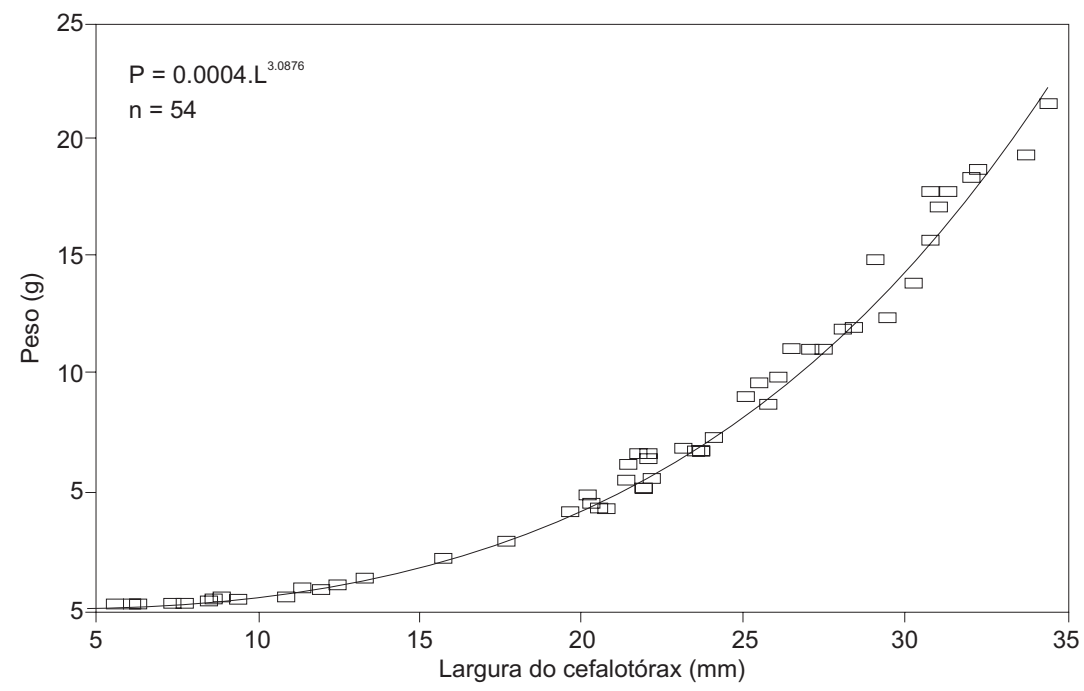

Fig. 10 - Relação entre o peso e a largura do cefalotórax de Ocypode quadrata, na praia de Pinhal, município de Balneário Pinhal, RS.

Era esperado, também, que o último mês de coleta (outubro) fosse complementado pelo primeiro (novembro), como um processo cíclico anual. No entanto, observando-se o gráfico, constata-se que não houve continuidade nos resultados, demonstrando prováveis alterações ambientais de um ano para o outro. O início do pico de jo- vens em janeiro pode indicar que o início do pico reprodutivo foi em novembro, o que confirma as deduções de Haley (1972) no que se refere ao pico de primavera. Como o próprio autor constatou, a maturidade de verão é menos sincronizada, sugerindo um tempo variável de recuperação e rematuração. 


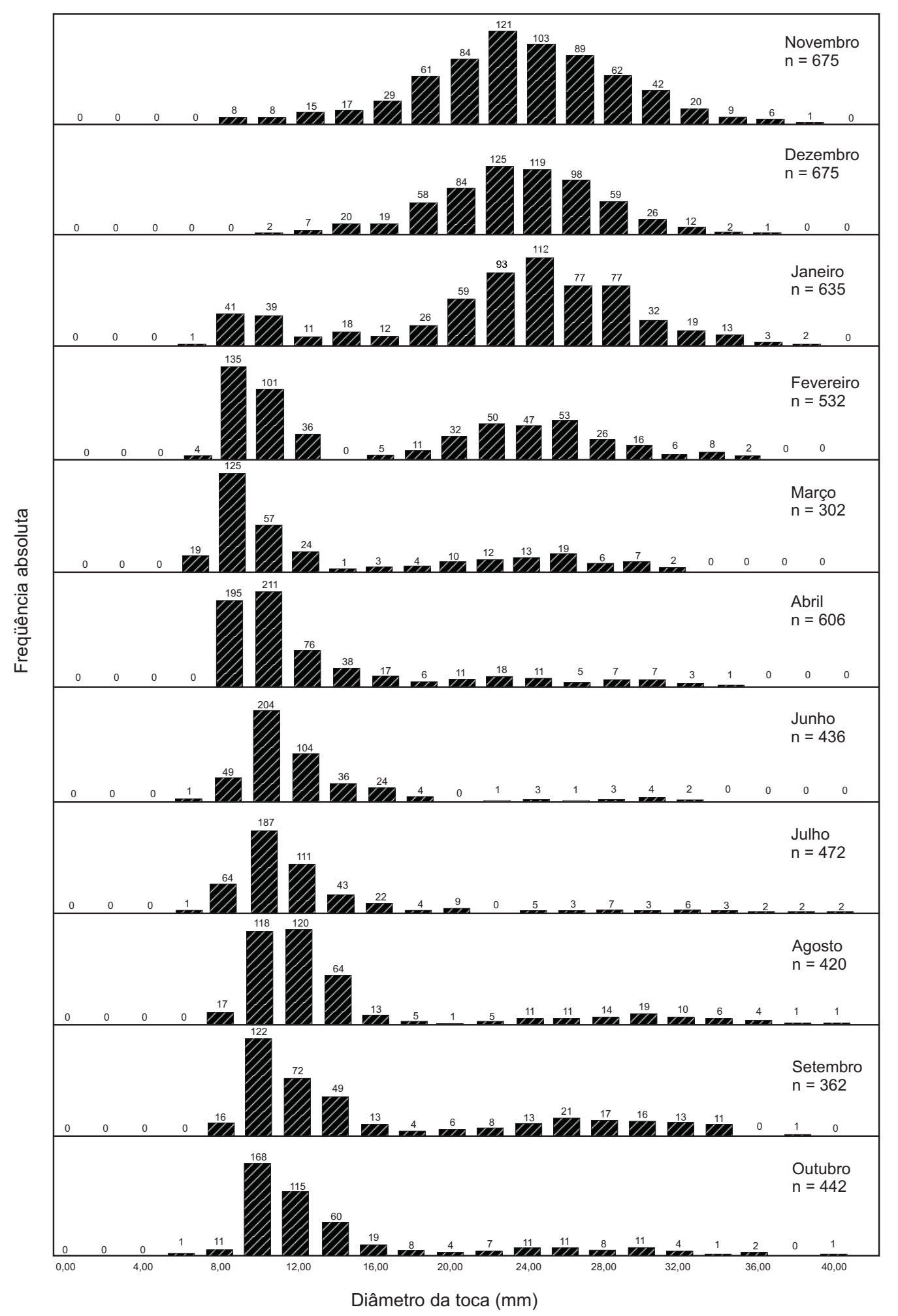

Fig. 11 - Distribuição mensal de freqüências de diâmetros de tocas de Ocypode quadrata, na praia de Pinhal, município de Balneário Pinhal, RS (período de novembro de 91 a outubro de 92). 
Esta heterogeneidade de maturação das fêmeas é representada por um período reprodutivo muito longo. Os animais menores que aparecem nos meses de fevereiro e março (nascidos, portanto, em dezembro e janeiro anteriores) podem ser indicadores do pico de maturação de verão, citado por Haley (1972). O gráfico bimodal informa, ainda, a presença de dois grupos etários distintos e uma expectativa de vida em torno de 2 anos, o que é bem visível nos meses de janeiro a outubro. O tamanho médio de cada grupo etário, a cada mês do ano, está representado na Tabela 1 . O mês de março foi a época em que se registraram tocas com diâmetro médio inferior a todos os outros meses, no que se refere ao primeiro grupo etário (grupo 0), que corresponde a animais que ainda não atingiram 1 ano de vida. Estes dados reforçam a existência do pico reprodutivo de verão, quando maior quantidade de jovens ingressam na população, diminuindo o tamanho médio do grupo. Nos meses de novembro e dezembro, com os dados obtidos, visualiza-se apenas um grupo etário. No entanto, comparando-se os dados, pode-se deduzir que estes tamanhos médios de diâmetros de tocas $(22,89 \mathrm{~mm}$ e $22,92 \mathrm{~mm})$ correspondem a indivíduos, em sua maioria, com idades próximas a 1 ano de vida, entrando em processo de reprodução.

A presença de exemplares grandes, com tamanhos bem superiores à média do segundo grupo etário, em cada mês, sugere ainda a existência de alguns indivíduos que poderiam atingir o terceiro ano de idade. Esta constatação é reforçada por Haley (1972) que deduziu que as fêmeas de caranguejofantasma vivem quase 3 anos, sendo juvenis durante o primeiro ano de vida. $\mathrm{O}$ segundo grupo etário da população em estudo deve incluir, portanto, indivíduos em maturidade sexual, apresentando larguras médias de carapaça a partir de $23 \mathrm{~mm}$.

Agradecimentos - Ao Prof. Dr. Jeter Bertoletti, Diretor do Museu de Ciências e Tecnologia da PUCRS (MCTPUCRS), pela autorização para o desenvolvimento deste trabalho nas dependências do Museu. À Biól. Esp. Carmem Freitas, do Laboratório de Botânica do MCTPUCRS, pela identificação do material botânico.

TABELA 1

Diâmetros máximo, mínimo e médio de tocas por grupo etário de Ocypode quadrata, aferidos mensalmente na praia de Pinhal, RS.

\begin{tabular}{|c|c|c|c|c|}
\hline \multirow{2}{*}{ Meses } & \multirow{2}{*}{$\begin{array}{c}\text { Tamanho } \\
\text { máximo }\end{array}$} & \multirow{2}{*}{$\begin{array}{c}\text { Tamanho } \\
\text { mínimo }\end{array}$} & \multicolumn{2}{|c|}{ Tamanho médio } \\
\hline & & & Grupo 0 & Grupo 1 \\
\hline Novembro/ 91 & 36,50 & 6,40 & 22,89 & - \\
\hline Dezembro/ 91 & 34,20 & 9,70 & 22,92 & - \\
\hline Janeiro/ 92 & 36,70 & 6,00 & 9,30 & 24,27 \\
\hline Fevereiro/ 92 & 36,00 & 6,00 & 9,22 & 24,48 \\
\hline Março/ 92 & 32,00 & 5,20 & 8,79 & 24,11 \\
\hline Abril/ 92 & 32,80 & 6,20 & 10,07 & 24,24 \\
\hline Junho/ 92 & 32,00 & 6,00 & 11,01 & 27.71 \\
\hline Julho/ 92 & 39,00 & 6,00 & 11,17 & 30,90 \\
\hline Agosto / 92 & 40,40 & 7,20 & 11,75 & 28,88 \\
\hline Setembro/ 92 & 36,50 & 7,00 & 11.47 & 27,54 \\
\hline Outubro/ 92 & 39,00 & 6,00 & 11,67 & 27,10 \\
\hline
\end{tabular}

\section{REFERÊNCIAS BIBLIOGRÁFICAS}

COUES, E., 1871, Notes on the Natural History of Fort Macon, N.C., and vicinity (no 2). Proc. Acad. Nat. Sci. Phila., Philadelphia, 23(1): 120-148.

COWLES, R. P., 1908, Habits, reactions, and associations in Ocypode arenaria. Papers from the Tortugas Laboratory of Carnegie Institution of Washington, Washington, (2)1: $1-41$.
CRANE, J., 1940, On the post-embrionic development of Brachyuran crabs of the genus Ocypode. Eastern Pacific Expeditions of New York Zoological Society, XVIII, Zoologica, New York, 25(6): 65- 82.

DUNCAN, G. A., 1986, Burrows of Ocypode quadrata (Fabricius) as related to slopes of substrate surface. $J$. Paleontol., Lawrence, 60(2): 384-389.

FABRICIUS, J. C., MAYOU, T. V., 1971, Decapod burrows in Holocene barrier island beaches and washover fans, Georgia. Senchenbergiana Maritima, vol. 3, pp. 53-77. 
FALES, R. R., 1976, Apparent predation on the mole crab Emerita talpoida (Say) by the ghost crab Ocypode quadrata (Fabricius). Chesapeake Sci., Solomons., 17(1): 65.

FISHER, J. B. \& TEVESZ, M. J. S., 1979, Within-habitat spatial patterns of Ocypode quadrata (Fabricius) (Decapoda, Brachyura). Crustaceana, suppl., 5, Leiden, pp. 31-36.

HALEY, S. R., 1969, Relative growth and sexual maturity of the Texas ghost crab, Ocypode quadrata (Fabricius) (Brachyura, Ocypodidae). Crustaceana, Leiden, 17(3): 285-297.

HALEY, S. R., 1972, Reprodutive cycling in the ghost crab Ocypode quadrata (Fabricius) (Brachyura, Ocypodidae). Crustaceana, Leiden, 23: 1-11.

KOEPCKE, H. W., 1953, Contribucion al conocimiento de la forma de vida de Ocypode gaudichaudii Milne Edwards et Lucas (Decapoda, Crust.) Publicaciones del Museu de Hist. Natural "Javier Prado", serie A, Zool., Lima, 13: 1-46.

LEBER, K. M., 1982, Seasonality of macroinvertebrate on a temperate, high wave energy sandy beach. Bull. of Marine Science, Coral Gable, 32(1): 86-98.

MILNE, L. J. \& MILNE, M. J., 1946, Notes on the behavior of the ghost crab. The American Naturalist, Chicago, 80(792): 362-380.

PHILLIPS, A. M., 1940, The ghost crabs - adventures investigating the life of a curious and interesting creature that lives on our doorstep, the only large crustacean of our North Atlantic coast that passes a good part of his life on land. Natural History, New York, 43: 36-41.

POWERS, L. W., 1977, A catalogue and bibliography to the crabs (Brachyura) of the Gulf of Mexico. Contrib. Mar. Sci., Port Aransas, 2: 140-142.

RAMOS-PORTO, M., FERREIRA-CORREIA, M. M. \& SOUSA, N. R., 1978, Levantamento da fauna aquática da Ilha de São Luís (Estado do Maranhão, Brasil). II Crustacea. Boletim do Laboratório de Hidrobiologia, São Luís, 2(1): 77-89.
RATHBUM, M. J., 1918, The grapsoid crabs of America. Bulletin of United States National Museum, Washington, 97: $461 \mathrm{p}$

ROBERTSON, J. R. \& PFEIFFER, W. J., 1982, Deposit feeding by the ghost crab Ocypode quadrata (Fabricius). J. Exp. Mar. Biol. Ecol., Amsterdan, 56: 165-177.

SAWAYA, P., 1939, Animais cavadores da praia arenosa. Arq Inst. Biol. São Paulo, São Paulo, 10: 319-326.

SANTOS, E., 1982, O Mundo dos Artrópodes. Itatiaia Ltda, Belo Horizonte, pp. 105-179 (Coleção Zoologia Brasílica, Vol. 8).

SCHMITT, W. L., 1968, Crustaceans. 2a ed., Ambassador Book Ltda., Rexdale, pp.133-134.

SCHÖNE, H., 1968, Agonistic and sexual display in aquatic and semi-terrestrial Brachyuran crabs. Am. Zool., Lawrence, 8 : 641-654.

STEINER, A. J. \& LEATHERMAN, S.P. 1981, Recreationa impacts on the distribution of ghost crabs Ocypode quadrata (Fabricius). Biol. Conserv., Barking, 20: 111-122.

TAKAHASI, S., 1935, Ecological notes on the ocypodian crabs (Ocypodidae) in Formosa, Japan. Annot. Zool. Japon., Tokyo, 15(1): 78-87.

TOMAZELLI, L. J. \& VILLWOCK, J. A., 1992, Considerações sobre o ambiente praial e a deriva litorânea de sedimentos ao longo do litoral norte do Rio Grande do Sul, Brasil. Pesquisas, Porto Alegre, 19(1): 3-12.

WILLIAMS, A. B., 1984, Shrimps and crabs of the Atlantic Coast of the Eastern United States, Maine to Florida. Smithsonian Institution Press, Washington, 550p.

WOLCOTT, T. G., 1978, Ecological role of ghost crabs, Ocypode quadrata (Fabricius) on an ocean beach: scavengers or predators? J. Exp. Mar. Biol. Ecol., Amsterdan, 31: $67-82$.

WOLCOTT, T. G. \& WOLCOTT, D. L., 1984, Impact of offroad vehicles on macroinvertebrates of a Mid-Atlantic beach. Biol. Conserv., Barking, 29: 217-240. 